\title{
CUANTIFICACIÓN DE AZÚCARES REDUCTORES DEL SUSTRATO EN RESIDUOS DE PIN̂A CON EL MÉTODO DEL ÁCIDO 3,5-DINITROSALICÍLICO
}

QUANTIFICATION OF SUBSTRATE REDUCING SUGARS IN PINEAPPLE RESIDUES USING THE 3,5DINITROSALICYLIC ACID METHOD

Lady Johanna Burgos Montañez*

FUNDACIÓN UNIVERSIDAD DE AMÉRICA

Recibido: 2 de septiembre de 2018

Aceptado: 24 de junio de 2019

DOI: https://doi.org/10.29097/23461098.308

\section{Resumen}

El desecho de piña posee gran cantidad de azúcares, que pueden aprovecharse para que los microorganismos los degraden y generen metabolitos o productos de fermentación. Trabajos relacionados utilizan el método propuesto por Miller (1959, pp. 426-428), que usa el ácido 3,5-dinitrosalicilico para determinar la concentración de azúcares reductores. En este ejercicio se aplicó este método, con el fin de determinar el contenido de azúcares reductores del sustrato en piña (Ananas cosmosus) en un caldo de fermentación con Lactobacillus acidophillus (o lactobacilo acidófilo) mediante un método experimental, agregando ácido 3,5-dinitrosalicílico o DNS a cada muestra. Este es un método colorimétrico para determinar absorbancias de luz a una longitud de onda de $540 \mathrm{~nm}$. Se preparó inicialmente el reactivo DNS, se elaboró una curva de calibración de glucosa con diferentes concentraciones. También se tomaron las muestras de caldo fermentado y se procedió a agregar el ácido 3,5-dinitrosalicílico a cada solución de glucosa y cada muestra. Además, se determinaron las absorbancias de cada solución en un espectrofotómetro. En la curva de calibración se obtuvo un coeficiente de correlación igual a 0,993. Así se alcanzaron valores en las concentraciones de sustrato desde 2,773 g/L hasta 4,654 g/L. Se evidenció un coeficiente de correlación cercano a 1, que indica la perfecta correlación entre datos. Además, se observó que a medida que aumentó el tiempo de la fermentación, la concentración de azúcares reductores disminuyó. El método de Miller mostró un alto coeficiente de correlación, siendo un método efectivo para la determinación de azúcares reductores en piña.

Palabras clave: azúcares, sustratos, fermentación, métodos colorimétricos, absorbancia.

\footnotetext{
* Estudiante de Ingeniería Química. El trabajo es producto del Semillero de investigación en procesos de separación no convencionales, línea de investigación procesos de separación con reacción.

凶 lady.burgos@estudiantes.uamerica.edu.co
} 
Abstract

Pineapple waste has a large number of sugars, which can be used by microorganisms to degrade them and generate metabolites or fermentation products. Related works apply the method proposed by Miller, which uses 3,5-dinitrosalicylic acid to determine the concentration of reducing sugars. In this exercise, the Miller's method was employed to determine reducing sugars of the substrate in pineapple (Ananas cosmosus) presented in a fermentation broth with Lactobacillus acidophillus using an experimental method that adds 3,5-dinitrosalicylic acid or DNS to each sample. It is a colorimetric method to determine light absorbances at a wavelength of $540 \mathrm{~nm}$. The DNS reactant was initially prepared, a glucose calibration curve was prepared with different concentrations. Samples were taken from the fermented broth. 3,5-dinitrosalicylic acid was added to each glucose solution and each sample. Besides, the absorbances of each solution were determined in a spectrophotometer. A correlation coefficient equal to 0,993 was obtained in the calibration curve. The values of the substrate concentrations were reached in a range between $2,773 \mathrm{~g} / \mathrm{L}$ to $4,654 \mathrm{~g} / \mathrm{L}$. A correlation coefficient close to 1 was found, which indicates the perfect correlation between data. Also, as the fermentation time increased, the concentration of reducing sugars decreased. Miller's method showed a high correlation coefficient, being an effective method for the determination of reducing sugars in pineapple.

Keywords: sugars, substrates, fermentation, colorimetric techniques, absorbance.

\section{INTRODUCCIÓN}

Los residuos agroindustriales han sido manejados como sustratos para la producción de metabolitos y productos de fermentación por medio de microorganismos capaces de degradar el sustrato y valerse de las fuentes de carbono (Granda et al. 2005). El estudio presentado aprovecha residuos de piña como sustrato para la producción de ácido láctico por la bacteria Lactobacillus acidophilus.

El ácido láctico es un ácido hidroxicarboxílico de gran importancia en la industria, utilizado para regular la acidez en alimentos como yogures, quesos, dulces, carnes, entre muchos otros (Serna, 2005). También es una aplicación en la industria farmacéutica y en la industria del plástico, en la industria química como solvente, agente limpiador y neutralizante, entre otras (García, 2010).

En este trabajo se busca determinar la cantidad de azúcares reductores que pueden ser obtenidos por la bacteria Lactobacillus acidophillus, empleando el método de Miller con el ácido 3,5-dinitrosalicílico o DNS. El reactivo DNS reacciona únicamente con azúcares reductores presentes en la muestra mediante una reacción redox (Miller, 1959). La importancia de este método radica en su alta sensibilidad y facilidad de obtención debido a que es una técnica espectrofotométrica (Rivers et al. 1984).

Según los estudios revisados, la mayoría de otros investigadores aplica el método de Miller. Dubois et al. (1956) evaluaron diferentes reactivos para detectar azúcares reductores. Lindsay (1973) realizó el método colorimétrico con el reactivo DNS para la 
determinación de azúcares reductores en papas. Blakeney y Mutton (1979) describen un método para la determinación de glucosa, fructosa y sacarosa en fruta y vegetales, además reportan el cuidado al proceder con el calentamiento y enfriamiento. Breuil y Saddler (1984) compararon el método de DNS con el de Nelson-Somogyi. Refieren que el método DNS demostró ser más fácilmente influenciado por las condiciones de incubación y por los componentes derivados de sustratos lignocelulósicos. Bello et al. (2006) compararon el método DNS con el de Eynon-Lane para determinación de azúcares reductores totales en jugos mezclados de caña de azúcar, siento el método DNS en frío más productivo con altos coeficientes de correlación.

Mejía et al. (2007) efectuaron pruebas de concentración de azúcares totales, reductores al residuo del mango común en la obtención de azúcares fermentables. Gusakov et al. (2011) compararon el método de DNS con el de Nelson-Somogyi en actividades de carbohidrasa. Registran que los dos métodos proporcionan datos muy similares cuando la actividad de la celulosa es medida contra CMC. Domínguez et al. (2011) recurren al método DNS para cuantificación de azúcares reductores en el bagazo de caña de azúcar. Ávila et al. (2012) manejan una técnica para la determinación del contenido de azúcares reductores en Agave cocui Trelease. Cortés et al. (2015) cuantificaron azúcares reductores en las cáscaras de naranja y banano; se evidencia mayor cantidad de azúcares reductores en las de naranja que en las de banano.

En este estudio se muestran el procedimiento y las condiciones estipuladas para la cuantificación de los azúcares reductores en los desechos de piña (Ananas cosmosus) como sustrato en la fermentación por la bacteria Lactobacillus acidophilus. La mayor parte de la piña posee sacarosa, fructosa y glucosa según datos reportados por Rashid (2008) y Krueger et al. (1992); los dos primeros son azúcares reductores; sin embargo, la glucosa es la fuente de energía de la bacteria Lactobacillus acidophillus, y su consumo puede determinarse utilizando el método DNS. El procedimiento inició con la toma de muestras de caldo fermentado y una curva de calibración de glucosa a diferentes concentraciones, se realizó la reacción del reactivo DNS con las muestras, se determinaron absorbancias a $540 \mathrm{~nm}$ en un espectrofotómetro, y se determinó la concentración de azúcares reductores presentes en las muestras.

\section{MATERIALES Y MÉTODOS}

Miller (1959) desarrolló un método para determinar azúcares reductores mediante el ácido 3,5-dinitrosalicílico, el cual reacciona con los azúcares reductores presentes en una muestra a través de calor, reduciendo el ácido a 3-amino-5 nitrosalicílico, y cambiando el color de la muestra que se oxida en apariencia amarilla-café. La cantidad de azúcares reductores en la muestra se puede determinar aplicando la ley de BeerLambert, que establece que la absorbancia se relaciona con las propiedades del analito, su concentración y la longitud del haz de radiación al atravesar la muestra (Swinehart,1962, pp. 333-335). Con el fin de hallar la absorbancia de la luz en la muestra a una longitud de onda de 540nm mediante espectrofotometría, se debe realizar una curva de calibración del patrón de glucosa que cuantifica la concentración de 
azúcares y reemplaza los valores de las absorbancias. Así se logra obtener la concentración de azúcares reductores. Al principio del método lo rige la ecuación 1:

$$
A=-\log _{10} \frac{P}{P_{O}}=a b c
$$

Donde $A$ es la absorbancia; $P$, la intensidad; $a$, la absortividad o coeficiente de extensión; $b$, la longitud del haz en el medio absorbente, y $c$, la concentración de la especie absorbente.

Si la ley de Beer-Lambert se cumple en todo el intervalo de $c$ estudiado, se obtiene una línea recta en él llamada curva de calibrado. Con esta es posible realizar una regresión lineal para predecir la concentración de azúcares reductores en las muestras.

Estos pasos se realizaron siguiendo los protocolos propuestos en el Manual de laboratorio de procesos biotecnológicos de la Pontificia Universidad Javeriana ([PUJ] 2007).

\section{Preparación del reactivo DNS}

Se pesa 1,6 g de NaOH, 43,8 g de tartrato de Na-K y 1 g de ácido 3,5-dinitrosalicílico. Se agrega el $\mathrm{NaOH}$ a un vaso de precipitado con $50 \mathrm{ml}$ de agua destilada hasta disolver completamente, luego se agrega el tartrato de Na-K lentamente hasta disolver por completo la solución mediante agitación magnética, y se agrega el ácido 3,5dinitrosalicílico, protegiendo el reactivo de la luz con papel aluminio. En seguida, se afora la solución hasta $100 \mathrm{~mL}$ con agua destilada en un balón aforado de $100 \mathrm{~mL}$ y se deja en agitación toda la noche en un frasco ámbar (Miller, 1959; PUJ, 2011).

\section{Preparación de las soluciones patrón de glucosa para la curva de calibración}

Se prepara la solución patrón de glucosa con las siguientes concentraciones: 0; 0,5; 0,7; 1,$0 ; 1,5 ; 1,7$, y 2,0 g/L. Se añaden $0,25 \mathrm{~mL}$ de cada solución y $0,25 \mathrm{~mL}$ del reactivo DNS en tubos tapa rosca cubiertos con papel aluminio para proteger la reacción de la luz. Los tubos se colocan en un baño termostático a $92{ }^{\circ} \mathrm{C}$ por cinco minutos. Se detiene la reacción por enfriamiento en hielo por cinco minutos y se agrega 2,5 $\mathrm{ml}$ de agua destilada a cada tubo, se agita y se realiza la lectura de la absorbancia a $540 \mathrm{~nm}$ en el espectrofotómetro. La Tabla 1 muestra en resumen las cantidades agregadas de glucosa, reactivo y agua destilada para cada muestra: 
Tabla 1

Metodología para elaborar la curva patrón de glucosa

\begin{tabular}{lccccccc}
\hline \multirow{2}{*}{ Reactivo } & \multirow{2}{*}{ Blanco } & \multicolumn{7}{c}{ Concentración (g/L) } \\
\cline { 3 - 8 } & & $\mathbf{0 , 5}$ & $\mathbf{0 , 7}$ & $\mathbf{1 , 0}$ & $\mathbf{1 , 5}$ & $\mathbf{1 , 7}$ & $\mathbf{2 , 0}$ \\
\hline Glucosa (mL) & - & 0,25 & 0,25 & 0,25 & 0,25 & 0,25 & 0,25 \\
\hline Agua (mL) & 0,25 & - & - & - & - & - & - \\
\hline Reactivo DNS (mL) & 0,25 & 0,25 & 0,25 & 0,25 & 0,25 & 0,25 & 0,25 \\
\hline Agua destilada (mL) & 2,5 & 2,5 & 2,5 & 2,5 & 2,5 & 2,5 & 2,5 \\
\hline
\end{tabular}

\section{Toma de muestras}

Durante el proceso de fermentación se tomaron muestras del caldo cada doce horas, desde 0 horas hasta 108 horas, una vez tomadas las muestras se refrigeraron para detener la reacción. Se realizó una réplica de la fermentación y se denominó al primer caldo de fermentación como A y a la réplica B.

\section{Determinación de la concentración de azúcares reductores en las muestras}

Se centrifugaron las 20 muestras de caldo de fermentación por ocho minutos a 4000 revoluciones por minuto. Se añadieron $0,25 \mathrm{~mL}$ de muestra y $0,25 \mathrm{~mL}$ del reactivo DNS en tubos tapa rosca cubiertos con papel aluminio para proteger la reacción de la luz. Los tubos se colocan en un baño termostático a $92{ }^{\circ} \mathrm{C}$ por cinco minutos. Se detiene la reacción con enfriamiento en hielo por otros cinco minutos y se agregan 2,5 ml de agua destilada a cada tubo, se agita y se realiza la lectura de la absorbancia a $540 \mathrm{~nm}$ en el espectrofotómetro.

Se realizó una regresión lineal a la curva de calibración, se despejó la variable concentración en función de la absorbancia medida, y se reemplazaron los datos obtenidos.

\section{RESULTADOS Y DISCUSIÓN}

\section{Curva de calibración de glucosa}

Luego de preparar las soluciones de glucosa y hacerlas reaccionar con el DNS, se procedió a medir las absorbancias de las soluciones de glucosa de 0,$5 ; 0,7 ; 1 ; 1,5 ; 1,7$, y $2 \mathrm{~g} / \mathrm{L}$ en un espectrofotómetro y graficar los resultados (véase Figura 1). La curva de calibración se realizó para determinar la concentración de azúcares reductores en las muestras de caldo fermentado, y cuantificar y monitorear los azúcares presentes durante 
el proceso de fermentación. La medición de la absorbancia se realizó de 0 a 1 , el valor 0 indica que no se absorbe nada de luz, y el 1 señala que absorbe toda la luz; sin embargo, algunas soluciones daban valores mayores a 1, por lo tanto, se realizaron diluciones de las soluciones de glucosa 1/10, con el fin de que la lectura de la absorbancia estuviera entre los valores.

\section{Figura 1}

Curva patrón de glucosa

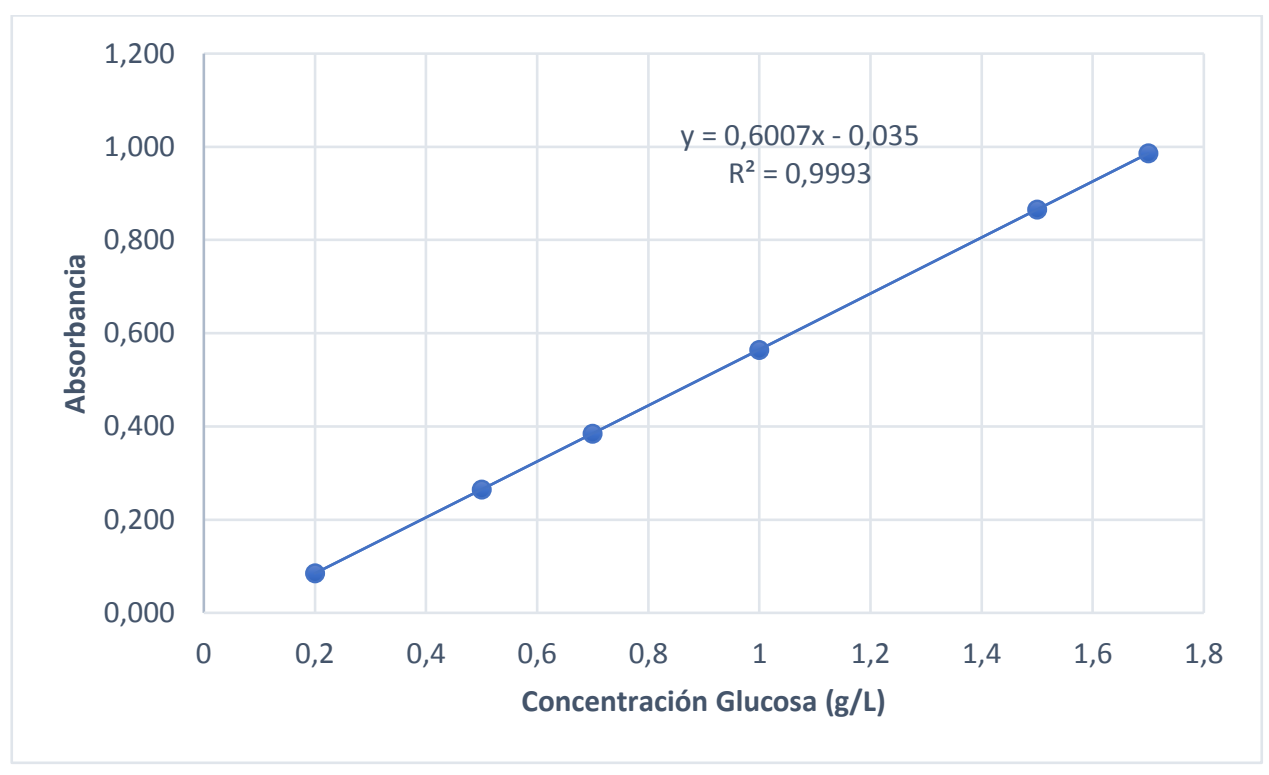

Nota. Gráfica de elaboración propia.

Al graficar los datos y determinar la ecuación de la recta y el coeficiente de correlación $\left(\mathrm{R}^{2}\right)$, se observa un valor igual a 0,9993 . Un coeficiente de correlación cercano a 1 indica perfecta correlación entre los datos al relacionar la concentración con la absorbancia y alta confiabilidad en los datos obtenidos, así como señala un procedimiento experimental efectivo al preparar las soluciones de análisis, es decir, se alcanzan las cantidades estipuladas, protegiendo las muestras de la luz natural.

La ecuación de la recta obtenida por regresión lineal en la Figura 1 es la herramienta esencial para la determinación de la concentración de azúcares reductores en las muestras de caldo de fermentación. Se despejó la variable de concentración en función de la absorbancia, siendo la variable x la concentración, y la variable y, la absorbancia.

$$
\mathrm{x}=\frac{\mathrm{y}+0,035}{0,6007}
$$




\section{Determinación de azúcares reductores del sustrato de pin̂̀a}

Se procedió a medir las absorbancias de las muestras de A y B en un espectrofotómetro. Las concentraciones de azúcares reductores para cada muestra en A y B respecto al tiempo usando el método DNS se obtuvieron bajo la ecuación de la regresión lineal (1), en la cual se despejó la variable concentración y se reemplazaron los valores de las absorbancias alcanzadas a una longitud de onda de $540 \mathrm{~nm}$.

En las muestras de A, las concentraciones de azúcares reductores tienen un máximo de 4,66 g/L al inicio de la fermentación y finalizan con una concentración mínima de $3,18 \mathrm{~g} / \mathrm{L}$ en la hora 108, mientras que, en las muestras de $\mathrm{B}$, las concentraciones de azúcares reductores tienen un máximo de 4,66 g/L al inicio de la fermentación y finalizan con una concentración mínima de 2,78 g/L en la hora 108. Tanto A como B inician con la misma concentración de azúcares reductores, pero B finaliza con una concentración menor que la de A. Asimismo se puede apreciar que la concentración en A y B disminuye al aumentar el tiempo. Desde el punto de vista microbiológico, esto indica que las bacterias están consumiendo el sustrato como fuente de energía para producir los compuestos por metabolismo, por lo tanto, los valores obtenidos concuerdan con esta teoría. La Figura 2 muestra las curvas de la concentración de azúcares reductores respecto al tiempo para cada muestra de A y B:

\section{Figura 2}

Consumo de sustrato en $A$ y $B$ vs. Tiempo

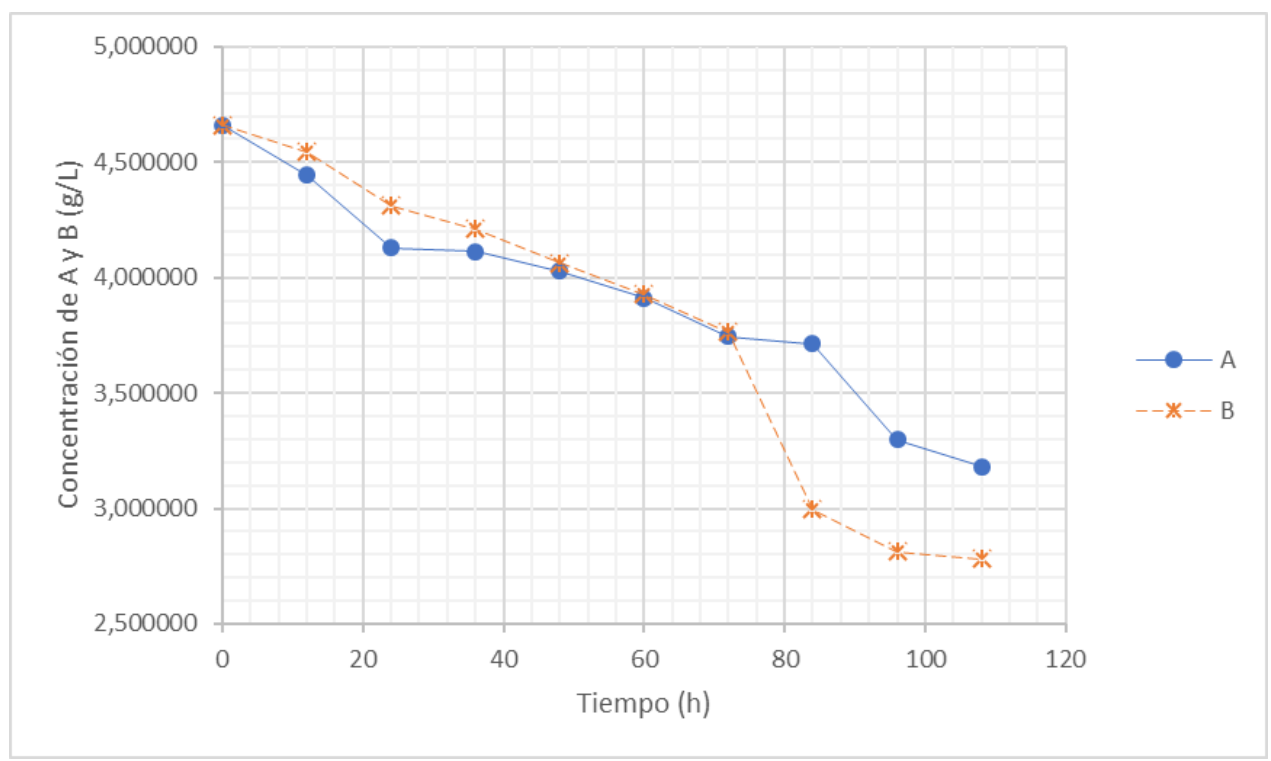

Nota. Gráfica de elaboración propia. 
En la Figura 2 se observa que la concentración de azúcares reductores en A disminuye rápidamente en las primeras horas de fermentación; sin embargo, de 20 a 36 horas la disminución es menor, lo mismo se observa al llegar a la hora 72: existen dos puntos en los cuales la disminución de azúcares es pequeña; se trata de sistemas sensibles a condiciones de cambio, llámense temperatura, humedad, presión, etcétera. Lo anterior los hace sistemas inestables, donde es de suma importancia el control, el mantenimiento de buenas condiciones de operación, agitación, temperatura constante, condiciones asépticas, con el fin de contrarrestar el efecto negativo al que están expuestos los microorganismos.

Por otra parte, B muestra una disminución de azúcares reductores más uniforme que A al aumentar el tiempo. En todo momento se presenta un agotamiento de sustrato por parte de la bacteria Lactobacillus acidophillus, una buena señal para la producción de ácido láctico de forma satisfactoria. De la misma manera se evidencia el alto consumo de los azúcares durante los primeros dos días, debido a que la velocidad de reacción es más alta en las primeras horas de fermentación con el caldo más altamente concentrado en azúcares.

\section{CONCLUSIONES}

El residuo de piña es un sustrato potencial para la producción de ácido láctico por Lactobacillus acidophilus, ya que se evidenció el consumo y aprovechamiento durante la fermentación de glucosa en piña (Figura 2). Además, posee otros nutrientes como proteínas y vitaminas que ayudan a la bacteria a lograr la producción de este metabolito.

Se estableció un procedimiento para la determinación de azúcares reductores en residuos de piña por el método del ácido 3,5-dinitrosalicilico para las fermentaciones realizadas en A y B. Utilizando este método, se obtuvo un alto coeficiente de correlación $\left(\mathrm{R}^{2}\right)$ entre la variable concentración y la absorbancia, indicado con un valor de 0,9993 y considerado el método efectivo para la determinación de azúcares reductores en piña.

Se logró determinar la concentración de azúcares reductores en piña (Figura 2), en donde se evidencia mayor gasto de glucosa en la fermentación B que en A por Lactobacillus acidophillus, posiblemente se presentó por las condiciones de operación y porque los sistemas biológicos son muy sensibles a pequeños cambios de concentraciones, temperatura, $\mathrm{pH}$, entre otros. Desde el punto de vista microbiológico pudo ocurrir muerte de unas pocas bacterias en estos dos puntos en la fermentación A, y por lo tanto no se agotó en la misma cantidad.

Asimismo, se puede apreciar que la concentración en A y B disminuye al aumentar el tiempo. Desde el punto de vista microbiológico, las bacterias consumen el sustrato como fuente de energía para producir los compuestos por vía metabólica, por lo tanto, los valores obtenidos corroboran esta teoría.

Este método experimental de laboratorio se podría reproducir en diversidad de sustratos, con el propósito de continuar investigando la cantidad de azúcares y fuentes de carbono aprovechables por los microorganismos para la producción de metabolitos con aplicaciones industriales. 


\section{Referencias}

Ávila, R., Rivas, B., Hernández, R., y Chirinos, M. (2012). Contenido de azúcares totales, reductores y no reductores en Agave cocui Trelease. Multiciencias, 12(2), pp. 129-135. https://www.redalyc.org/pdf/904/90424216002.pdf

Bello, D., Carrera, E., y Díaz, Y. (2006). Determinación de azúcares reductores totales en jugos mezclados de caña de azúcar utilizando el método del ácido 3,5 dinitrosalicílico. $\quad$ ICIDCA, $40 \quad$ (2), $\quad$ pp. $\quad$ 45-50. https://www.redalyc.org/articulo.oa?id=223120664006

Blakeney, A. B., y Mutton, L. L. (1980). A simple colorimetric method for the determination of sugars in fruit and vegetables. Journal of the Science of Food and Agriculture, 31(9), pp. 889-897. https://doi.org/10.1002/jsfa.2740310905

Breuil, C., y Saddler, J. N. (1984). Comparison of the 3,5-dinitrosalicylic acid and Nelson-Somogyi methods of assaying for reducing sugars and determining cellulase activity. Enzyme and Microbial Technology, 7(7), pp. 327-332. https://doi.org/10.1016/0141-0229(85)90111-5

Cordon, S. (2016). Ajuste de un modelo matemático para el crecimiento de Streptococcus pygenes en dos sustratos para la producción de ácido hialurónico a escala de laboratorio. (Trabajo de grado). Fundación Universidad de América.

Cortes, W., Ibla, J., Calderón, L., y Herrera, A. (2015). Cuantificación de azúcares reductores en las cáscaras de naranja y banano. Revista de Tecnología, 12(2), pp. 72-76. https://doi.org/10.18270/rt.v12i2.772

Domínguez, M. M., Álvarez Castillo, A., Castrejón Rosales, T., Granados Baeza, M., Hernández Campos, F., Alcalá Octaviano, V., y Tapia Picazo, J. (2011). Estudio de la cinética de la hidrólisis ácida del bagazo de caña de azúcar sin pretratamiento para la obtención de azúcares reductores. Revista Iberoamericana de Polímeros, 12(3), pp. 153-159. http://www.ehu.eus/reviberpol/pdf/MAY11/dominguez.pdf

Dubois, M., Gilles, E., Hamilton, J. K., Rebers, P., y Smith, F. (2002). Colorimetric Dubois method for determination of sugars and related substances. Analytical Chemistry, 18(3), pp. 350-356. DOI: 10.1021/ac60111a017

García, C., Arrázola, G., y Durango, A. (2010). Producción de ácido láctico por vía biotecnológica. Temas Agrarios, 15(2), pp. 9-26. DOI: 10.21897/rta.v15i2.676

Granda R, D. M., Mejía G, A. I., y Jiménez T, G. A. (2005). Utilización de residuos de plátano para la producción de metabolitos secundarios por fermentación en estado sólido con el hongo Lentinus crinitus. Vitae, 12(2), pp. 13-20. http://www.scielo.org.co/pdf/vitae/v12n2/v12n2a02.pdf

Gusakov, A., Kondratyeva, E., y Sinitsyn, A. (2011). Comparison of two methods for assaying reducing sugars in the determination of carbohydrase activities. International Journal of Analytical Chemistry, 2011, pp. 1-4. doi:10.1155/2011/283658

Krueger, D., Krueger, R., y Maciel, J. (1992). Composition of pineapple juice. Journal International AOAC, 75 (2), pp. 280-282. 
Lindsay, H. (1973). A colorimetric estimation of reducing sugars in potatoes with 3,5dinitrosalicylic acid. Potato Research, 16, pp. 176-179. https://doi.org/10.1007/BF02356048

Mejía, L. F., Martínez Correa, H. A., Betancourt, J. E., y Castrillón, C. E. (2007). Aprovechamiento del residuo agroindustrial del mango común (Mangifera indica L.) en la obtención de azúcares fermentables. Ingeniería y Ciencia, 3(6), pp. 41-62. https://www.redalyc.org/articulo.oa?id=83530603

Miller, G. (1959). Use of dinitrosalicylic acid reagent for determination of reducing sugar. Analitycal Chemistry, 31 (3). pp. 426-428. https://doi.org/10.1021/ac60147a030

Pontificia Universidad Javeriana. (2007). Manual de laboratorio de procesos biotecnológicos. Universidad Javeriana.

Rashid, R. (2008). Optimization and Modeling of Lactic Acid Production from Pineapple Waste. Final Report. Technological University of Malaysia.

Rivers, D. B., Gracheck, S. J., Woodford, L. C., y Emert, G. H. (1983). Limitations of the DNS assay for reducing sugars from saccharified lignocellulosics. Biotechnology and Bioengineering, 26, pp. 800-802. DOI: 10.1002/bit.260260727

Serna, L., y Rodríguez, A. (2005). Producción biotecnológica de ácido láctico: estado del arte. Ciencia y Tecnología Alimentaria, 5(1), pp. 54-65. https://www.redalyc.org/articulo.oa?id=72450109

Swinehart, D. (1962). The Beer-Lambert Law. Journal of Chemical Education, 39(7), pp. 333-335. https://doi.org/10.1021/ed039p333 